\title{
EXTENDING FATIGUE LIFE OF CRACKED OUT-OF-PLANE GUSSET BY ICR TREATMENT
}

\author{
Toshiyuki ISHIKAWA ${ }^{1}$, Kentaro YAMADA ${ }^{2}$, Takumi KAKIICHI ${ }^{3}$ and $\mathrm{Hui}^{4}{ }^{4}$ \\ ${ }^{1}$ Member of JSCE, Assistant Professor, Dept. of Urban Management, Kyoto University \\ (Kyotodaigaku-katsura, Nishikyo-ku, Kyoto 615-8540, Japan) \\ E-mail: ishikawa.toshiyuki.2e@kyoto-u.ac.jp \\ ${ }^{2}$ Member of JSCE, Dept. Emeritus Professor, Nagoya University \\ (Furo-cho, Chikusa-ku, Nagoya 464-8603, Japan) \\ E-mail: yamada@civil.nagoya-u.ac.jp \\ ${ }^{3}$ Member of JSCE, JFE Engineering (Former graduate student of Nagoya University) \\ (2-1,Suehiro-cho,Tsurumi-ku,Yokohama 230-8611, Japan) \\ E-mail: kakiichi-takumi@jfe-eng.co.jp \\ ${ }^{4}$ Student Member of JSCE, Graduate Student, School of Engineering, University of Tokyo \\ (Former student of Nagoya University) \\ (7-3-1 Hongo, Bunkyo-ku, Tokyo 113-0033, Japan)
}

\begin{abstract}
Various types of fatigue cracks have been found in steel bridges. To maintain steel bridges, repair and retrofit methods of such fatigue cracks have been developed. The authors developed a technique which generates plastic deformation of steel surface near the crack in order to close crack opening by an impact air tool. This method is called Impact Crack Closure Retrofit treatment (ICR treatment). Plate bending fatigue tests of out-of-plane gusset specimens were carried out. Fatigue cracks at turn-around welds and those which have propagated 10 and $20 \mathrm{~mm}$ were ICR-treated. Fatigue test results showed significant improvement in the fatigue life of specimens due to ICR treatment.
\end{abstract}

Key Words : ICR treatment, out-of-plane gusset plate, plate bending, fatigue strength improvement

\section{INTORODUCTION}

Various types of fatigue cracks have been found at welded joints in steel highway bridges in Japan due to heavy truck traffic including illegally overloaded trucks. Those fatigue cracks are usually repaired and retrofitted after investigation of the cause of cracking. However, small cracks, which do not impose immediate danger to the bridges, are often left as they are because of high retrofit cost. In order to avoid such situation, it is necessary to develop inexpensive repair techniques for such small cracks, as well as fatigue strength improving technique for welded joints. Well-known fatigue strength improving techniques include reducing stress concentration, inducing residual compressive stress near the weld toe and bypassing the stress near the crack.

Weld toe grinding ${ }^{1)}$ and TIG-dressing ${ }^{2)}$ can improve weld geometry and reduce stress concentration. To reduce structural stress concentration, smoothing the stress state by drilling hole near the weld is often applied.

Shot peening ${ }^{4), 5)}$ and Hammer peening ${ }^{2)}$ are well-established techniques to induce residual compressive stress at weld toe. Ultrasonic Impact Treatment (UIT) can also induce residual compressive stress at weld toe ${ }^{6}$.

Bolting the splice plates near the cracks is generally used as a means of repair. Besides this, repair by resin injection has also been proposed ${ }^{7}$. Recently, carbon fiber reinforced polymer strips have been applied as a bypass repair method ${ }^{8)}$.

The authors have developed one technique which generates plastic deformation of steel surface near the crack in order to close the crack opening by using an impact air tool ${ }^{9,10)}$. This method is named as Impact Crack Closure Retrofit treatment (ICR treatment). Using commercially available tools, it could be simplified the technique and achieved relatively low cost of operation.

In order to verify the effectiveness of ICR treatment, fatigue test of out-of-plane gusset specimens, which have the similar structural detail as the vertical stiffeners welded to orthotropic steel deck, were carried out. Fatigue test results confirmed the feasibility of ICR treatment for retrofitting fatigue cracks 
found at weld toe in steel structures.

\section{ICR TREATMENT}

\section{(1) Process of ICR treatment}

In order to close fatigue crack surface, the side of crack was plastically deformed by an impact air tool, as shown in Fig. 1. For fatigue cracks initiated and propagated at weld toe, main plate in front of weld toe line was plastically deformed by ICR treatment. For the crack propagated into the main plate, the crack was closed by peening both sides of the crack and right on top of the crack, as shown in Fig. 1(b).

\section{(2) Device of ICR treatment}

The device used for ICR treatment is shown in Fig. 2 which consisted of an impact air tool, a chisel and an air compressor. The chisel tip was grounded to a flat rectangular surface of $4 \times 5 \mathrm{~mm}$ with its corners rounded. A handy type impact air tool with a hammering frequency of $90 \mathrm{~Hz}$, pin stroke of $16 \mathrm{~mm}$ and air consumption volume of $0.14 \mathrm{~m}^{3} / \mathrm{min}$ was adopted for ICR treatment. An air compressor with a tank capacity of 10 liter supplies air to the impact tool. In this device, the air pressure is maintained at about 0.6 MPa during ICR treatment.

\section{FATIGUE TEST OF OUT-OF-PLANE GUSSET SPECIMEN WITH ICR TREATMENT}

\section{(1) Test specimen}

The specimens used in fatigue test are shown in Fig. 3. Material properties and chemical compositions of steel plate used for test specimens are listed in Table 1.

The specimens resembled turn-around fillet welds between orthotropic steel deck and vertical stiffener of steel box girders. The gusset plate of 100 or 300 $\mathrm{mm}$ high and $12 \mathrm{~mm}$ thick was welded to the main plate of $300 \mathrm{~mm}$ wide and $12 \mathrm{~mm}$ thick. The fillet-weld of $6 \mathrm{~mm}$ leg length was installed by $\mathrm{CO}_{2}$ gas shielded semi-automatic arc welding. SE-50T (JIS Z 3312 YGW12) metal was used in the welding. The measured leg lengths were between 8 to $10 \mathrm{~mm}$ on the main plate and 5 to $8 \mathrm{~mm}$ on the gusset plate. The local radius of weld toe on the main plate was $0.2 \mathrm{~mm}$ and the angle of weld was approximately 140 degree.

\section{(2) Fatigue test}

Fatigue tests were carried out using a fatigue testing machine that generated a plate bending type of loading ${ }^{11}$, as shown in Fig. 4. One end of the specimen was fixed to the test bed, and the other end was subjected to loading by a vibrator. A set of two springs was screwed down to generate the tension-tension loading or stress ratio $R>0$. The spring stiffness was sufficient to maintain pre-loading during the fatigue test. To monitor stress range, strain gages were placed at a distance of $12 \mathrm{~mm}$ away from the weld toe (A) and $75 \mathrm{~mm}$ away from the bead

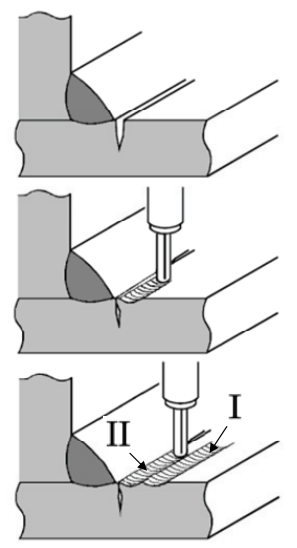

(a) Weld toe crack

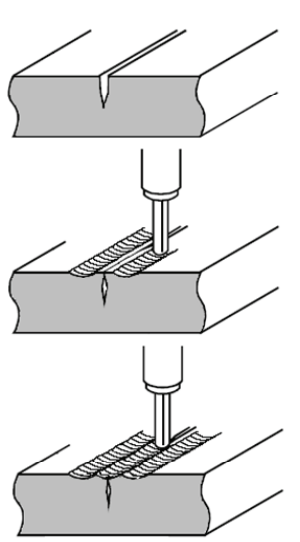

(b) Surface crack
Fig. 1 Process of ICR treatment.

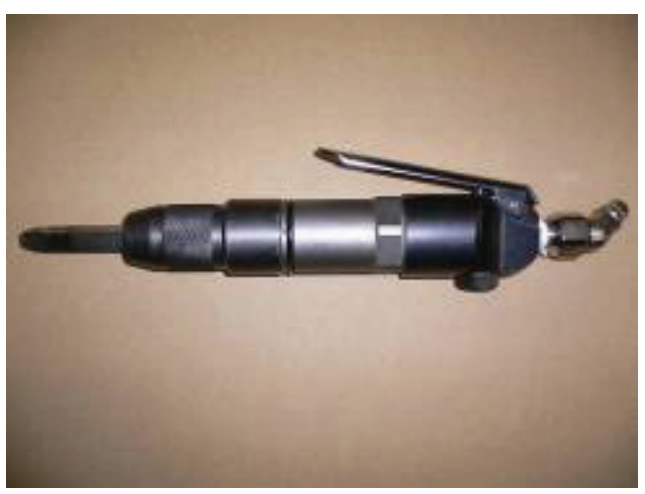

(a) Handy type of impact air tool

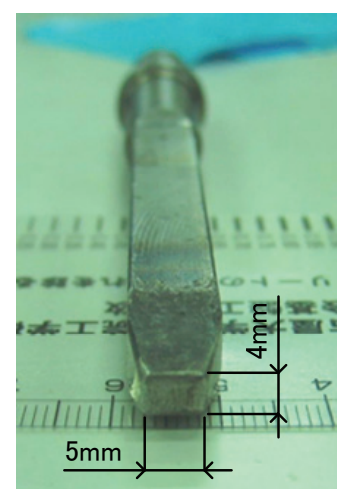

(b) Chisel tip

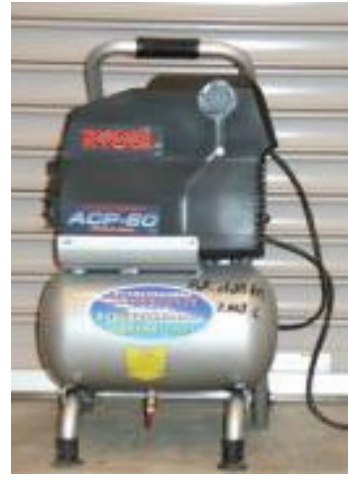

(c) Air compressor

Fig. 2 Device to be used for ICR treatment. 
Table 1 Material properties and chemical compositions.

\begin{tabular}{|c|c|c|c|c|c|c|c|}
\hline \multirow{2}{*}{ Steel } & \multirow{2}{*}{$\begin{array}{c}\text { Yield stress } \\
(\mathrm{MPa})\end{array}$} & $\begin{array}{c}\text { Tensile strength } \\
(\mathrm{MPa})\end{array}$ & \multicolumn{2}{|c|}{$\begin{array}{c}\text { Elongation } \\
(\%)\end{array}$} & \multicolumn{4}{|c|}{ Chemical compositions (\%) } \\
\hline SM490 & 344 & 523 & $\mathrm{C}$ & $\mathrm{Si}$ & $\mathrm{Mn}$ & $\mathrm{P}$ & $\mathrm{S}$ \\
\hline
\end{tabular}

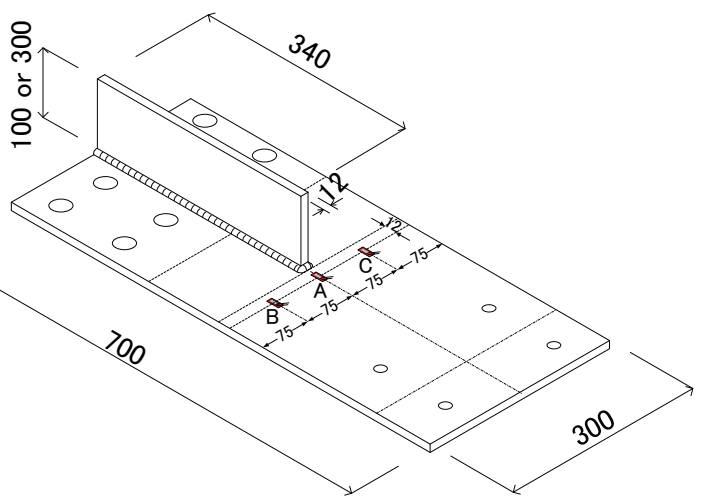

Fig. 3 Out-of-plane gusset specimen (unit: $\mathrm{mm}$ ).

center (B and C), as shown in Fig. 3.

During the plate bending fatigue test by vibrator, stress range became gradually higher as fatigue crack propagated. Therefore, by using the measured stresses at points $\mathrm{B}$ and $\mathrm{C}$, the equivalent stress range, which would be used for the $S-N$ diagram, could be calculated by the following equation.

$$
\Delta \sigma_{e q}=\left\{\sum\left(n_{i} \cdot \Delta \sigma_{i}{ }^{3}\right) / \sum n_{i}\right\}^{\frac{1}{3}}
$$

where, $\Delta \sigma_{e q}$ is the equivalent stress range (MPa), $\Delta \sigma_{i}$ is the measured average stress range at points $\mathrm{B}$ and $\mathrm{C}(\mathrm{MPa})$ and $n_{i}$ is the number of cycles during the measured interval of stress range $\Delta \sigma_{i}$.

Stresses at points A to $\mathrm{C}$ were measured for approximately 2 seconds with a sampling frequency of $2 \mathrm{kHz}$ at 10 or 20 minutes intervals during the fatigue test.

In the fatigue test of out-of-plane gusset specimen, the equivalent stress ranges, $\Delta \sigma_{e q}$, when the fatigue crack propagated to the weld edge became approximately 1.05 times higher than that recorded at the start of test. Furthermore, $\Delta \sigma_{e q}$ when the fatigue crack reached to $10 \mathrm{~mm}$ away from the weld toe became 1.15 times higher than that at the start of the test.

\section{(3) Definition of fatigue crack size}

To trace fatigue crack initiation and propagation behavior, shielded copper wires of $0.04 \mathrm{~mm}$ diameter were glued onto the weld bead and the surface of the main plate, and we could obtain fatigue life corresponding to those crack sizes, as shown in Fig. 5. They were $N_{t o e}, N_{b}, N_{10}$ and $N_{20}$, which corresponded to crack sizes, such as when a crack initiated at the weld toe, when the crack propagated off the fillet weld toe, when the crack propagated to 10 and 20

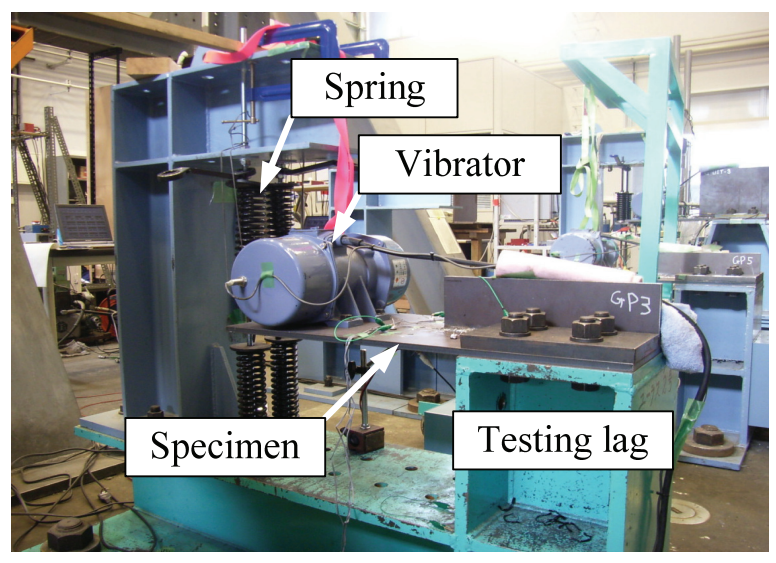

Fig. 4 Test set-up.

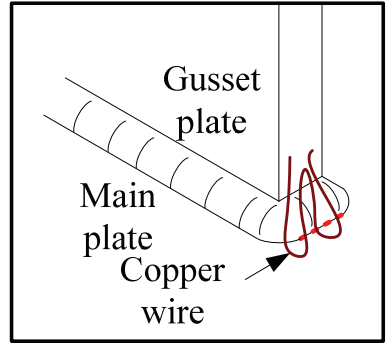

(a) $N_{\text {toe }}$

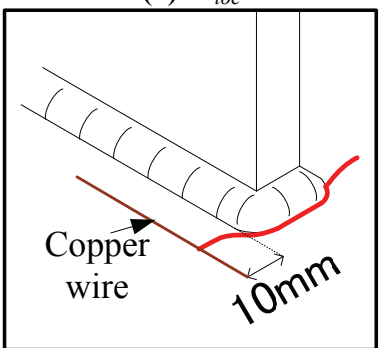

(c) $N_{10}$

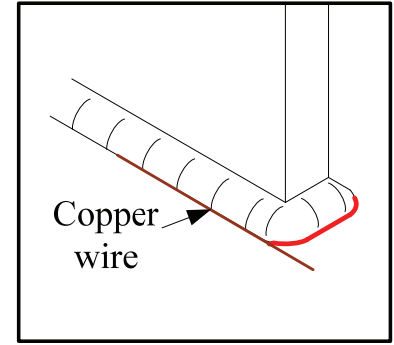

(b) $N_{b}$

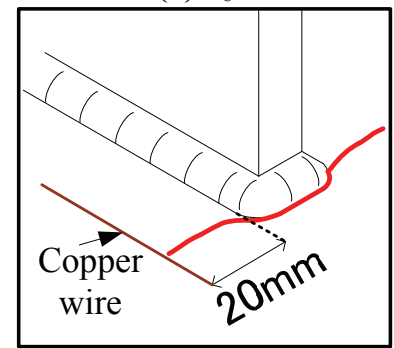

(d) $N_{20}$
Fig. 5 Definition of fatigue crack sizes.

mm long. In this study, $N_{f}$ is the number of cycles when the crack propagated to $30 \mathrm{~mm}$ long or when the through-thickness crack was observed.

The ICR treatment was carried out for the cracks corresponding to $N_{b}, N_{10}$ and $N_{20}$, and they are designated as $N_{b}+\mathrm{ICR}, N_{10}+\mathrm{ICR}$ and $N_{20}+\mathrm{ICR}$.

In specimen $N_{b}+\mathrm{ICR}$, ICR treatment was applied to the turn-around weld toe line only, as shown in Fig. 6(a). In specimen $N_{10}+\mathrm{ICR}$, cracks that propagated into the main plate were first plastically deformed by ICR treatment. Then, ICR treatment was carried out on the turn-around weld toe line, as shown in Fig. 6(b). 


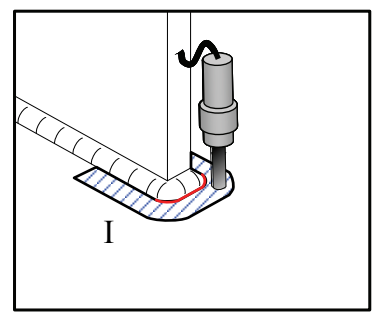

(a) $N_{b}$

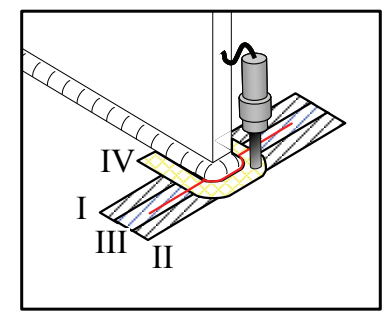

(b) $N_{10}, N_{20}$
Fig. 6 ICR treatment to out-of-plane gusset specimens.

The surface and cross section of ICR treated specimen are shown in Figs. 7 and 8, respectively. As a result of the treatment, dent lines were left on the surface of the main plate, as shown in Fig. 7. The measured depth of dent by a laser displacement sensor was 0.2 to $0.5 \mathrm{~mm}$. As can be seen from Fig. 8, ICR treatment has successfully closed approximately $1.2 \mathrm{~mm}$ of depth from the surface.

\section{(4) Test series}

Fatigue test series and designations of specimens are given as follows.

a) as-welded specimen:

Specimen which was not ICR treated.

b) $N_{b}+$ ICR specimen $(R=-1)$ :

Specimen which was ICR treated when the crack propagated off the fillet weld toe, $N_{b}$.

c) $N_{10}+$ ICR specimen $(R=-1)$ :

Specimen which was ICR treated when the crack propagated to $10 \mathrm{~mm}$ long from the weld toe, $N_{10}$.

d) preloading $+N_{10}\left(N_{20}\right)+$ ICR specimen $(R=0.4, R=0)$ :

First, fatigue crack of $N_{10}$ or $N_{20}$ were induced with a stress ratio of $R=0.4$ or $R=0$ by screwing down the spring. Then, ICR treatment was carried out under the preloading condition.

e) $N_{10}(R)+$ ICR specimen $(R=-1)$ :

In $N_{10}(R)+$ ICR specimen, fatigue cracks initiated at the weld root or weld toe on the gusset plate and propagated to $10 \mathrm{~mm}$ on the main plate are ICR treated. In this specimen, to prevent the initiation of fatigue crack from the weld toe, ICR treatment was carried out for as-welded conditions.

\section{FATIGUE TEST RESLUTS}

\section{(1) Stress condition on closed crack}

Fig. 9 gives the average stress at points $\mathrm{B}$ and $\mathrm{C}$, which were $75 \mathrm{~mm}$ away from the center, plotted against the stress at point $\mathrm{A}$, which was $12 \mathrm{~mm}$ away from the weld toe, after the ICR treatment. In this figure, the same relations measured for as-welded specimen and when the crack propagated to $N_{b}$ or $N_{10}$ are also plotted. For the as-welded specimen, higher stress was observed at point $\mathrm{A}$ than at points $\mathrm{B}$ and $\mathrm{C}$

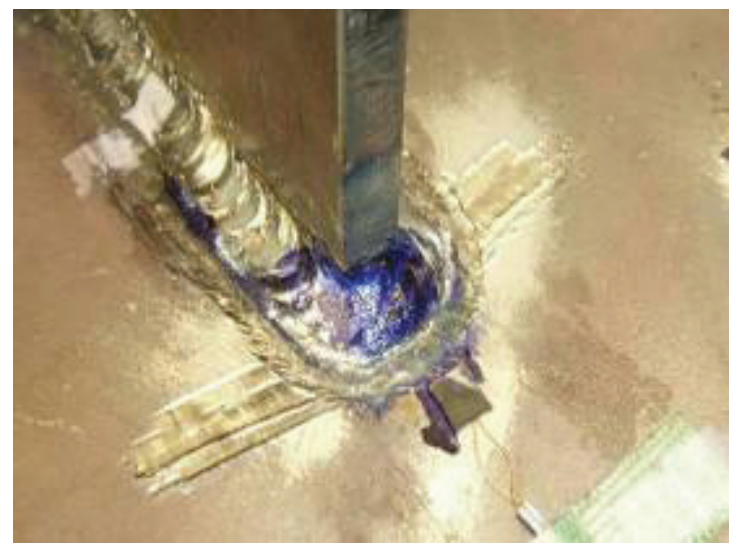

Fig. 7 Surface of specimen after ICR treatment.

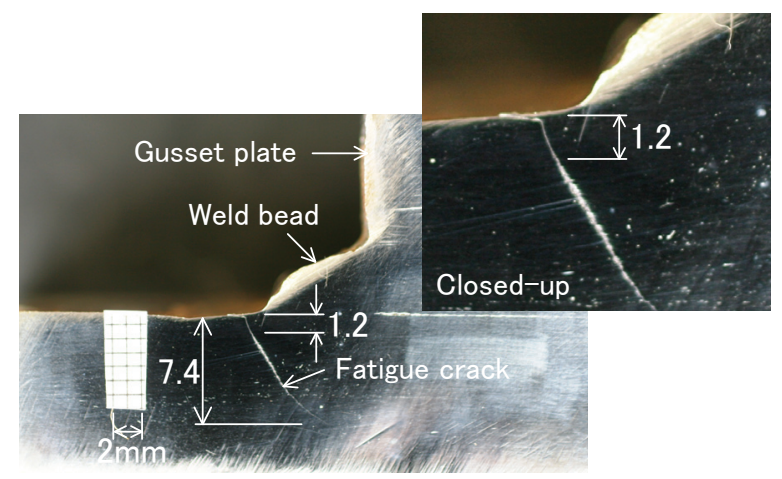

(a) Turn-around weld

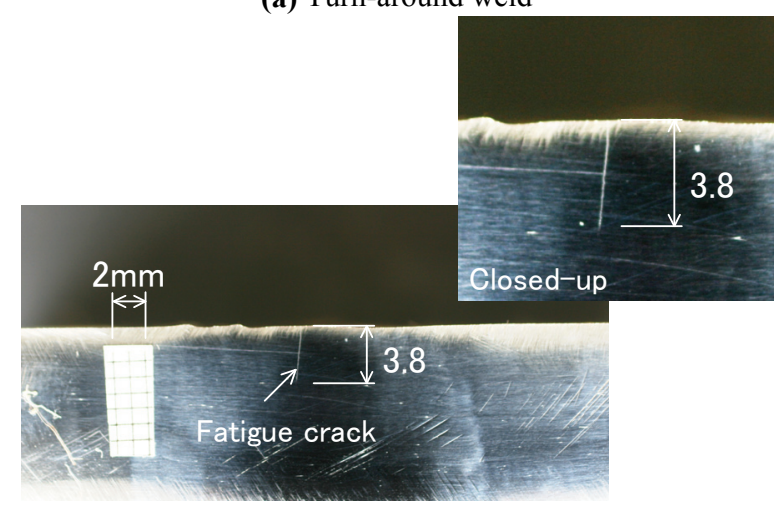

(b) Main plate (5mm away from weld toe line)

Fig. 8 Closed fatigue crack by ICR treatment.

due to stress concentration at the gusset end. Since the crack propagated corresponding to $N_{b}$ or $N_{10}$, the stress at point A became smaller, because the crack did not sustain the stress itself. When ICR treatment was carried out at $N_{b}$, however, the crack surface was closed and the slope becomes similar to the one obtained under the as-welded condition, as shown in Fig. 9(a). When the ICR treatment was carried out at $N_{10}$, the slope on compression stress region becomes similar to the one of the as-welded condition. The slope on tensile stress region shows the nonlinearity between the as-welded condition and the $N_{b}$ condition. It can be assumed that the stress concentration at weld toe was restored, because the crack surface was 


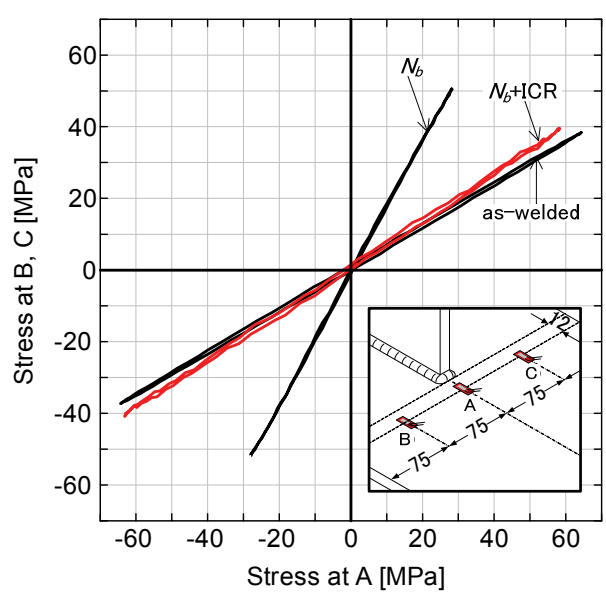

(a) $N_{b}+\mathrm{ICR}$

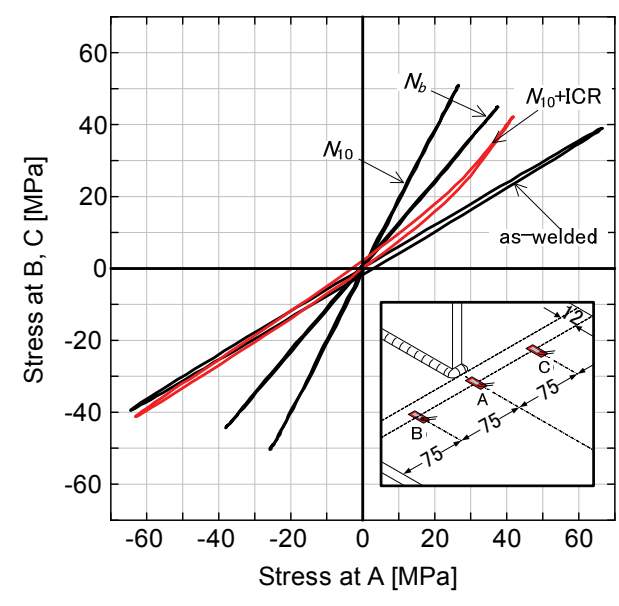

(b) $N_{10}+$ ICR

Fig. 9 Relation between average stress at B and C and stress at A.

closed by ICR treatment and the closed crack transmitted the stress again. Therefore, the ICR treated crack in the main plate was still closed, but the closed crack near the weld toe, which affected stress concentration, became partially open again.

\section{(2) $S$ - $N$ diagram}

\section{a) as-welded specimen}

Fatigue test results of $N_{b}, N_{10}$ and $N_{f}$, are plotted in Fig. 10. The results of as-welded specimens tested earlier ${ }^{5), 11)}$ are also plotted. In this figure, the design $S-N$ relations as specified in recommendation for fatigue design by $\mathrm{JSSC}^{12}$ ) are incorporated. There was no apparent difference between the test results obtained from this study and those obtained from earlier testing.

\section{b) $N_{b}+$ ICR specimen $(R=-1)$}

Fatigue test results of $N_{b}+$ ICR specimens are plotted in Fig. 11. The number of cycles indicates the cycles after ICR treatment. Those which did not fail after ten or twenty million cycles were re-tested at higher stress ranges, which are indicated by dotted lines. $S-N$ relations of the as-welded specimen with $\pm 2 s$ deviations are also illustrated in this figure.

In $N_{b}+$ ICR-2 specimen, copper wire on $N_{10}$ line was broken at 2.59 million cycles after ICR treatment under a stress range of $80.9 \mathrm{MPa}$. The crack, however, did not propagate until twelve million cycles. Therefore, test result of $N_{b}+\mathrm{ICR}-2$ specimen at $\Delta \sigma=80.9 \mathrm{MPa}$ was treated as run-out data. Using this specimen, fatigue test was restarted under a stress rage of $100 \mathrm{MPa}$. As a result, copper wire on the back surface of the main plate was broken by the fatigue crack opening. The fatigue strength of $N_{b}+\mathrm{ICR}$ specimen was approximately two categories higher than that of the as-welded specimens, in accordance to classification of JSSC. In addition, $N_{b}+\mathrm{ICR}$ specimen

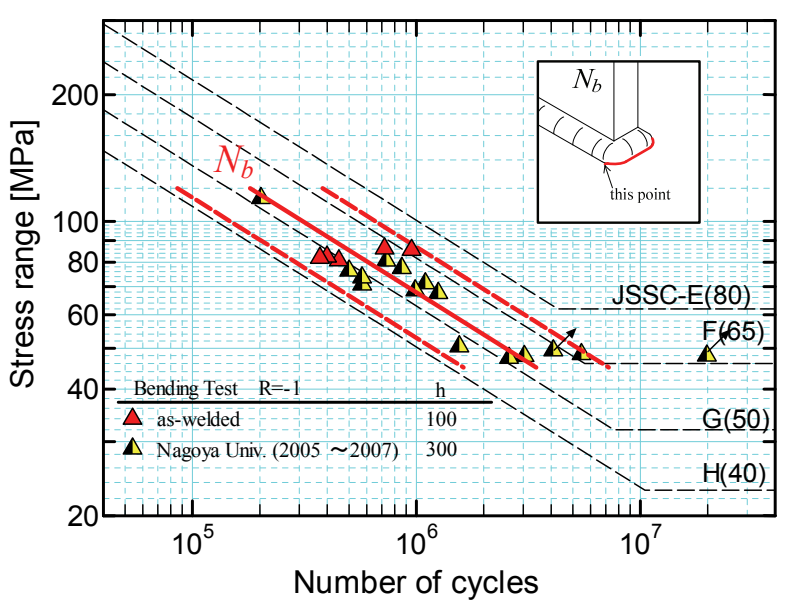

(a) $N_{b}$

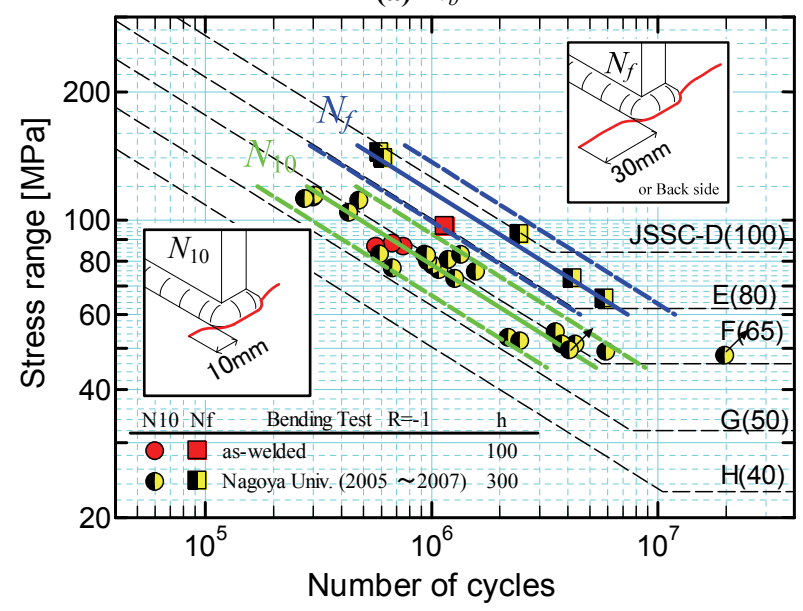

(b) $N_{10}, N_{f}$

Fig. $10 S-N$ relation of as-welded specimens.

was found to have fatigue strength higher than the base metal categorized in JSSC-C.

c) $N_{10}+$ ICR specimen $(R=-1)$

Fatigue test results of $N_{10}+\mathrm{ICR}$ specimens are 


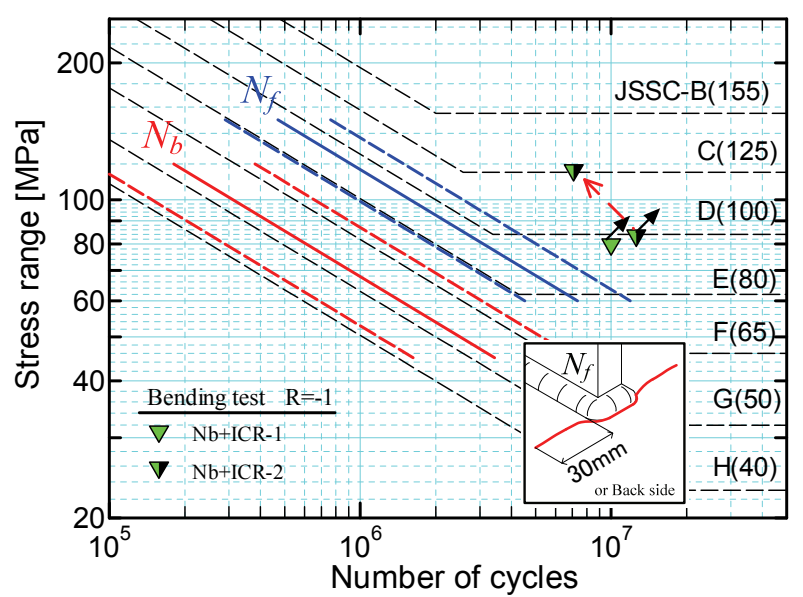

Fig. $11 S-N$ relation of $N_{b}+$ ICR specimens.

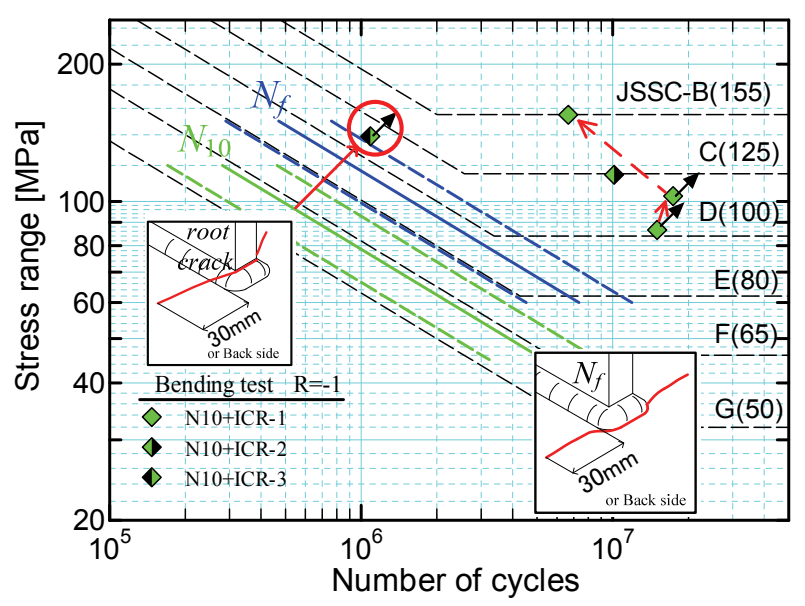

Fig. $12 S-N$ relation of $N_{10}+$ ICR specimens.

shown in Fig. 12. In $N_{10}+$ ICR-1 specimen, fatigue crack did not re-propagate after fifteen million cycles at $\Delta \sigma=87 \mathrm{MPa}$ and seventeen million cycles at $\Delta \sigma=103 \mathrm{MPa}$. The crack propagation was eventually found at a stress range of $155 \mathrm{MPa}$. In $N_{10}+$ ICR-2 specimen, fatigue crack re-propagate under higher stress range. In $N_{10}+$ ICR-3 specimen, however, root crack was created under high stress range, without opening the ICR treated toe crack.

The fatigue strength of specimens $N_{10}+$ ICR were also two categories higher than that of the as-welded specimens with reference to the classification of JSSC.

\section{d) preloading $+N_{10}\left(N_{20}\right)+$ ICR specimen $(R=0.4$, $\boldsymbol{R}=\mathbf{0}$ )}

Fatigue test results of preloading $+N_{10}\left(N_{20}\right)+\mathrm{ICR}$ specimens are plotted in Fig. 13. In preloading $+N_{10}+$ ICR -1 specimen, the ICR treated crack did not open after thirty million cycles at $\Delta \sigma=115 \mathrm{MPa}$. Then, fatigue test was restarted at a stress range of $168 \mathrm{MPa}$, and ICR treated crack re-propagated to 30 $\mathrm{mm}$ away from the weld toe. In preloading $+N_{10}+\mathrm{ICR}-2$ specimen, fatigue tests were carried

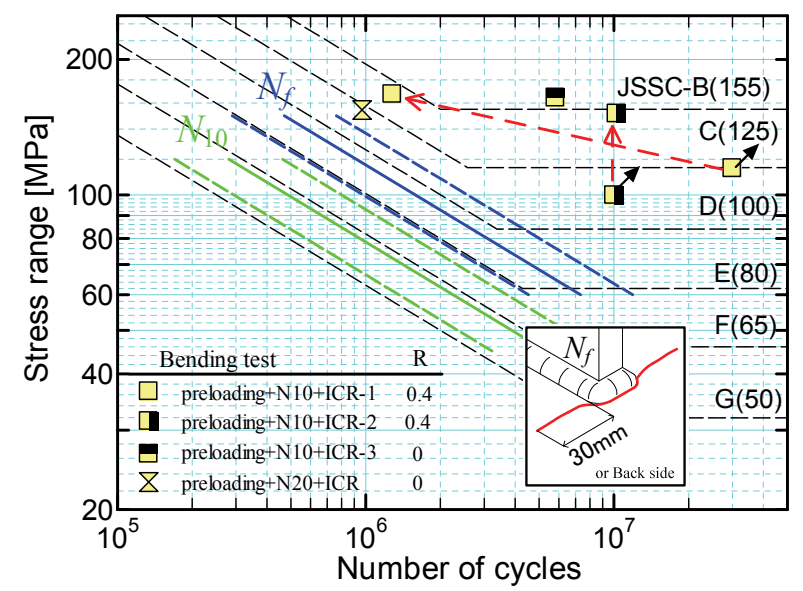

Fig. $13 S-N$ relation of preloading $+N_{10}\left(N_{20}\right)+$ ICR specimens.

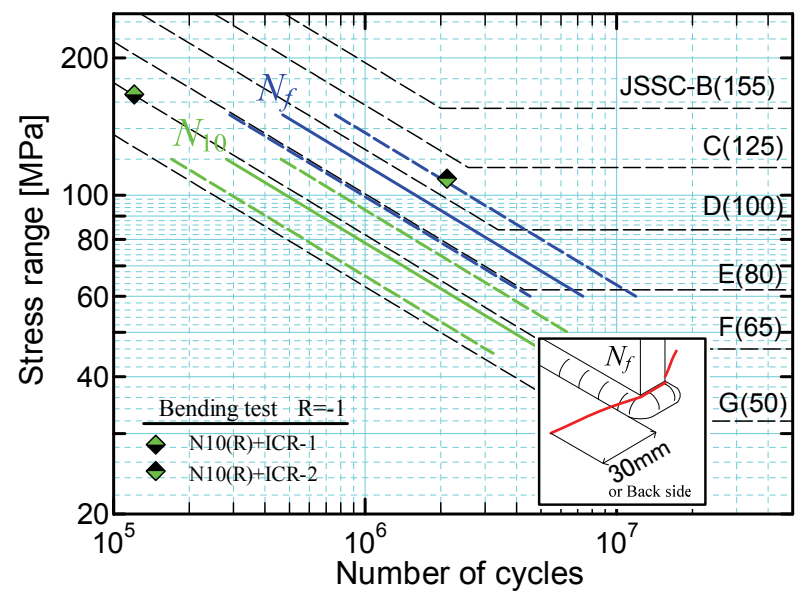

Fig. $14 S-N$ relation of $N_{10}(R)+$ ICR specimens.

out after run-out (ten million cycles) at $\Delta \sigma=100$ MPa. The closed crack became opening and the specimen failed after 10.2 million cycles at $\Delta \sigma=152$ MPa. In preloading $+N_{10}+$ ICR-3 specimen, the ICR treated crack also re-propagated at high stress range.

The fatigue strength of preloading $+N_{10}+$ ICR specimens is higher than JSSC-C category.

In preloading $+N_{20}+$ ICR specimen, fatigue crack re-propagated and its fatigue strength was slightly shorter than the JSSC-C category. However, it is shown that the ICR treatment is effective even for crack growth up to $N_{20}$, because the remaining fatigue life after $N_{20}$ in as-welded specimen was in general quite short.

e) $N_{10}(R)+$ ICR specimen $(R=-1)$

By ICR treatment at the weld toe of as-welded specimen, fatigue crack initiated from the weld root or weld toe on gusset plate. After the crack reached $N_{10}$, ICR treatment was carried out only for cracks on the main plate. Therefore, fatigue crack is closed only on the main plate.

Fatigue test results of $N_{10}(R)+\mathrm{ICR}$ specimen are plotted in Fig. 14. In $N_{10}(R)+$ ICR-1 specimen, which 


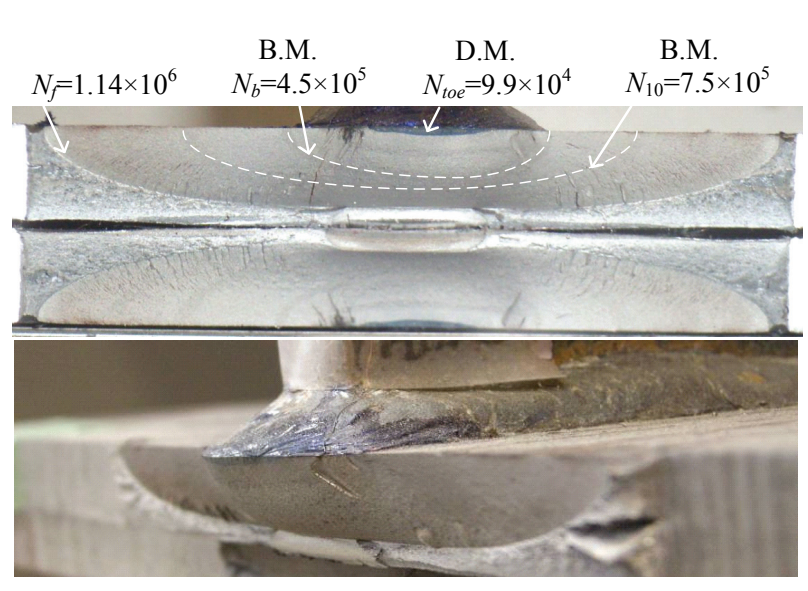

Fig. 15 Fracture surface of as-welded specimen.

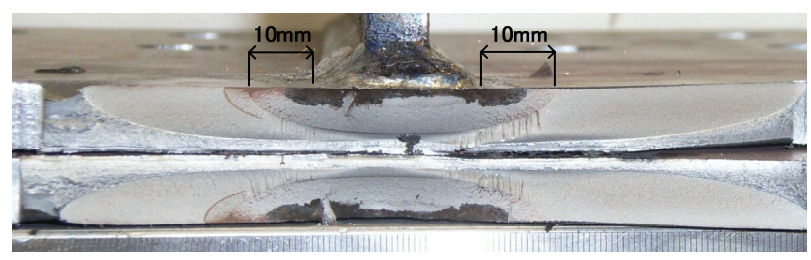

Fig. 16 Fracture surface of $N_{b}+\mathrm{ICR}-2$ specimen.

has crack initiated at the weld toe on the gusset plate, the fatigue crack re-propagated. Fatigue strength, $N_{f}$, of $N_{10}(R)+$ ICR-1 was categorized as JSSC-F and this was similar to $N_{10}$ of the as-welded specimens.

Accordingly, for members with fatigue crack initiating from the weld root or weld toe on the gusset plate and propagated into the main plate, the application of ICR treatment could help elongate of their remaining fatigue life.

\section{(3) Fracture surface}

Fatigue fracture surface of as-welded specimen is shown in Fig. 15. Dye marking was applied to shape the toe crack. The beach marks were also produced on $N_{b}$ and $N_{10}$ by lowering the applied stress range by about $60 \%$ of the applied stress range for one hundred thousand cycles. From this figure, it can be seen that the fatigue crack of as-welded specimen initiated at the weld toe of the turn-around weld and propagated in the main plate in a semi-elliptical shape. The propagation of fatigue crack on the thickness direction slowed down about $80 \%$ of the thickness of main plate, because of the bending type of fatigue loading, but fatigue crack on the surface of main plate still propagated. Additionally, as shown in Fig. 15, the crack propagated in three dimensions. The tendency of fatigue crack propagation in the as-welded specimen was almost the same as those tested earlier ${ }^{11)}$.

Fracture surface of $N_{b}+\mathrm{ICR}-2$ specimens is shown in Fig. 16. From this figure, it could be assumed that the surface of crack, which was indicated by brow-

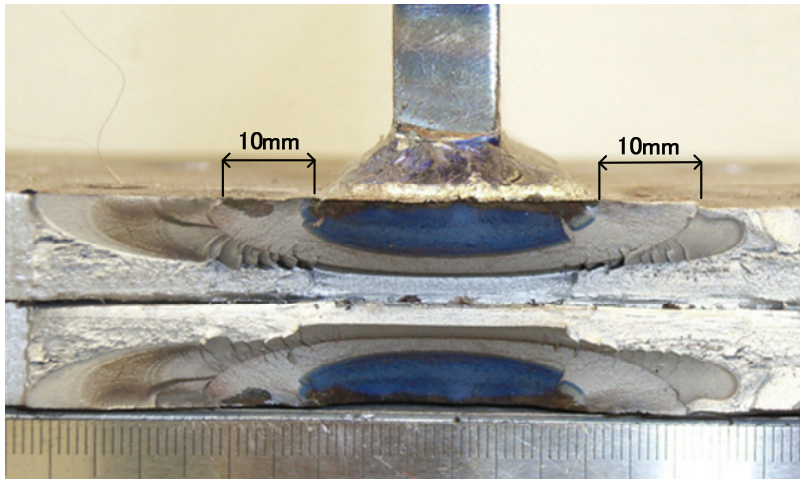

Fig. 17 Fracture surface of $N_{10}+$ ICR-1 specimen.

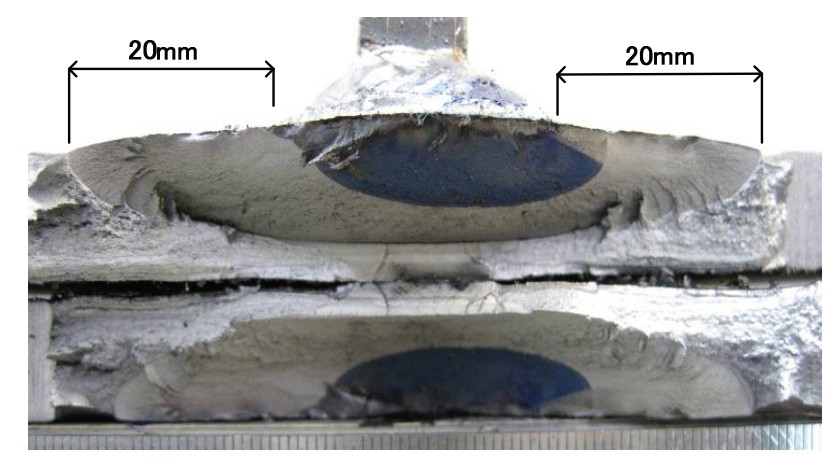

Fig. 18 Fracture surface of preloading $+N_{20}+$ ICR specimen.

nish regions near the surface of crack, was closed by ICR treatment. In this specimen, copper wire on $N_{10}$ line was broken during fatigue test at $\Delta \sigma=84 \mathrm{MPa}$, but after that the crack did not propagate further. However, beach mark curve could be observed near the $N_{10}$ line. Thus, it can be assumed that the crack has propagated until $N_{10}$ and then stopped at the stress range of $84 \mathrm{MPa}$.

Fracture surface of $N_{10}+\mathrm{ICR}-1$ specimen is depicted in Fig. 17. In this specimen, the dye marking was applied on $N_{b}$, as clearly shown in the figure. In the ICR treated specimen at $N_{10}$, the crack propagated inside of the main plate in a somewhat peculiar elliptical shape. It might be due to the reason that the surface of the crack has been closed by ICR treatment, and thus did not propagate during the fatigue test. As the crack became larger, at higher stress range in the re-tested condition, the internal crack finally propagated and appears at the plate surface.

Fracture surface of preloading $+N_{20}+$ ICR- 1 specimens is shown in Fig. 18. In this specimen, the dye marking was also applied on $N_{b}$ condition. In this figure, fatigue crack did not propagate after ICR treatment of $N_{20}$. However, fatigue crack initiated from the back surface on the main plate and broke the copper wire.

Accordingly, in the case of ICR treatment for larger crack ( $N_{20}$ or more), it is inferred that the crack initiated at the back surface on the main plate by 
cyclic loading even when the surface of crack was closed.

\section{CONCLUSIONS}

In order to verify the effectiveness of ICR treatment, fatigue test of out-of-plane gusset specimens, which was similar structural details to the vertical stiffeners welded to orthotropic steel deck, were carried out in this study. Fatigue test results showed significant improvement of the remaining fatigue life. The followings summarize the results obtained from the fatigue tests.

1) Stress measurement before and after ICR treatment revealed that the stress perpendicular to the crack, which was normally very small, was restored to the level equivalent to the case of no crack. It implies that the crack was closed and did not open at the applied stress range.

2) Fatigue tests of out-of-plane gusset specimens with fatigue cracks of $N_{b}$ and $N_{10}$ retrofitted by ICR treatment showed significant improvement of the remaining fatigue life.

3) ICR treated crack propagated inside of the main plate in a somewhat peculiar elliptical shape at higher stress range.

4) ICR treatment was also effective to improve the remaining fatigue life for cracks initiated under the stress ratio of $R=0.4$ or $R=0$.

5) In the case of the fatigue cracks initiated from the weld root or weld toe on the gusset plate and propagated to the main plate, ICR treatment could be carried out only for cracks on the main plate. In this case, ICR treatment could also help elongate the remaining fatigue life.

ACKNOWLEDGMENT: This study is supported by Nagoya Expressway Public Corporation. The authors acknowledged those who have rendered help at various stages, i.e. Dr. H. Oda of Takigami Steel Construction, Ltd. and Dr. S. Yamada of Topy Industry.

\section{REFERENCES}

1) Japan Road Association: Fatigue in Steel Bridges, 1997. (in Japanese)

2) Anami, K., Miki, C., Tani, H. and Yamamoto, H.: Improving fatigue strength of welded joints by hammer peening and TIG-dressing, Structural Eng./Earthquake Eng. JSCE, Vol.17, No.1, pp.57-68, 2000.

3) Miki, C., Sugimoto, I., Kaji, H., Negishi, H. and Ito, Y.: A study on fatigue strength improvement of flange gusset in existing steel railway bridges, Structural Eng./Earthquake Eng., JSCE, No.584/I-42, pp.67-77, 1998.

4) Hasegawa, M., Takeda, H. and Suzuki, H. : Improvement of fatigue strength of steel welded joint by shot peening, Preprints of the National Meeting of JWS, Vol.69, pp.476-477, 2001.

5) Yamada, K., Ojio, T., Torii, A., Baik, B., Sasaki, Y. and Yamada, S.: Influence of shot blasting on fatigue strength of out-of-plane gusseted specimens under bending, Journal of Structural Engineering, Vol.54A, pp.522-529, 2008. (in Japanese)

6) Nose, T. and Shimanuki, H. : Experiment and analysis of influence of ultrasonic peening on fatigue life in pad welded joint, The Japan Society of Mechanical Engineers (A), Vol.74, No.737, pp.166-168, 2008.

7) Tateishi, K., Kitagawa, K., Inaba, N. and Tomota, Y.: Fatigue crack propagation control by resin injection with local heating method, Doboku Gakkai Ronbunshuu A, Vol.62, No.1, pp.126-131, 2006. (in Japanese)

8) Nakamura, H., Moroi, T., Suzuki, H., Maeda, K. and Irube, T.: Repair of fatigue cracks in out-of-plane welded gusset joints using laminated CFRP strips, Journal of Construction Steel, Vol.13, pp.89-96, 2005. (in Japanese)

9) Yamada, K., Ishikawa, T., Kakiichi, T. and Li, H.: Development of elongation technique of fatigue life by closing fatigue crack, Procedings of Annual Conference of the Chubu Branch of JSCE, I-5, pp.9-10, 2009. (in Japanese)

10) Yamada, K., Ishikawa, T. and Kakiichi, T.: Extending fatigue durability by closing crack surface, Doboku Gakkai Ronbunshuu A, Vol. 65, No. 4, pp.961-965, 2009. (in Japanese)

11) Yamada, K., Osonoe, T. and Ojio, T.: Bending fatigue test on welded joint between vertical stiffener and deck plate, Steel Construction Engineering, Vol.14, No.55, 2007. (in Japanese)

12) Japan Society of Steel Constructions (JSSC): Fatigue Design Recommendations for Steel Structures, 1993. (In Japanese), 1995. (In English) 